\title{
Perbedaan Kenaikan Berat Badan pada Bayi yang Mendapat ASI Eksklusif dengan ASI Parsial di Puskesmas Jetis Kota
}

\author{
Asti Norma1 ${ }^{1}$ Ircham Machfoedz ${ }^{2}$, Oktaviana Maharani ${ }^{3}$
}

1,2,3 Sekolah Tinggi IImu Kesehatan Alma Ata Yogyakarta

Jalan Ringroad Barat Daya No 1 Tamantirto, Kasihan, Bantul, Yogyakarta

\begin{abstract}
Abstrak
Kondisi saat ini di negara berkembang sekitar 10 juta bayi mengalami kematian. Hal tersebut dapat ditekan dengan cara menyusui secara eksklusif karena Air Susu Ibu (ASI) sudah terbukti dapat meningkatkan status kesehatan bayi. Berdasarkan studi pendahuluan yang dilakukan di Puskesmas Jetis Kota, diperoleh hasil empat bayi yang mendapat ASI eksklusif mengalami kenaikan berat badan antara 4.800-6.100 gram sedangkan enam bayi yang mendapat ASI parsial mengalami kenaikan berat badan antara 3.350-5.250 gram. Tujuan penelitian ini untuk mengetahui perbedaan kenaikan berat badan pada bayi yang mendapat ASI eksklusif dan ASI parsial di Puskesmas Jetis Kota. Jenis penelitian ini induktif dengan rancangan penelitian cross-sectional. Cara pengambilan sampel menggunakan total sampling dengan jumlah sampel 20 pasangan ibu dan bayi yang telah mendapat ASI eksklusif dan Asi parsial. Penelitian ini dilakukan di Puskesmas Jetis Kota Yogyakarta bulan Februari sampai Maret 2015 dan dianalisis menggunakan analisis " $t$ " test. Hasil uji statistik menunjukkan kenaikan berat badan 210 gram lebih tinggi pada bayi yang mendapat ASI eksklusif, kenaikan berat badan bayi yang mendapat ASI eksklusif adalah 8.200 gram dan 7.990 gram pada bayi yang mendapat ASI parsial. Simpulan tidak terdapat perbedaan kenaikan berat badan yang signifikan pada bayi yang mendapat ASI eksklusif dan bayi yang mendapat ASI parsial.
\end{abstract}

Kata Kunci: ASI eksklusif, ASI parsial, perbedaan kenaikan berat badan bayi

\section{The Weight Gain Differences between Infants with Exclusive and Partial Breastfeeding}

\begin{abstract}
Current conditions in developing countries was approximately 10 million infants were dying. These may be pressed by exclusive breastfeeding, because breastfeeding has been proven to improve the health status of the baby. Based on the baseline study conducted in Puskesmas Jetis Kota, the results of four infants exclusively breastfed resulted in weight gain between 4.800 to 6.100 grams while six partially breastfed infants weight gain between 3.350 to 5.250 grams. The purpose of this study was to determine differences of weight gain in infants between exclusive and partial breastfeeding at Puskesmas Jetis Kota. The study was an inductive study with cross-sectional design. The sampling technique was done by total sampling resulting on 20 couples of mothers and babies who had been exclusively breastfed or received partialy breastfed. This study was conducted at Puskesmas Jetis Yogyakarta on February until March, 2015 and analyzed using " $t$ " test analysis. The results showed that weight gain of exclusively breastfed infants was 8.200 grams and the average of increase in weight gain in infants who are breastfed partial was 7.990 grams. There was 210 gram weight gain more higher in infants with exclusively breastfed. In conclusion, there was no significant differences weight gain in infants with exclusively breastfed and partially breastfed infants.
\end{abstract}

Keywords: exclusive breastfeeding, partial breastfeeding, weight gain in infants

Info Artikel:

Artikel dikirim pada 18 Mei 2015

Artikel diterima pada 20 Mei 2015 


\section{PENDAHULUAN}

Berdasarkan penelitian yang dilakukan di Dhaka, Bangladesh pada 1.667 bayi selama 12 bulan mengatakan bahwa ASI eksklusif dapat menurunkan resiko kematian akibat infeksi saluran nafas akut dan diare(1). Hasil dari Riskesdas tahun 2010, persentase menyusui pada bayi umur 0 bulan adalah sebanyak $39,8 \%$ menyusui eksklusif $5,1 \%$ menyusui predominan dan menyusui parsial sebanyak $55,1 \%$. Pada bayi yang berumur 5 bulan menyusui eksklusif hanya $15,3 \%$, menyusui predominan $1,5 \%$ dan menyusui parsial $83,2 \%(2)$.

Berdasarkan laporan Dinas Kesehatan Provinsi tahun 2013, sebaran cakupan pemberian ASI eksklusif pada bayi 0-6 bulan di Indonesia sebesar $54,3 \%$. Sedangkan cakupan ASI eksklusif di Provinsi DIY adalah sebesar $67,9 \%$, dan cakupan bayi yang diberi ASI eksklusif di kabupaten Bantul tahun 2013 sebesar 62,05\%(3). Di Kabupaten Sleman tahun 2012, cakupan ASI eksklusif mencapai 70,4\%(4).

Berdasarkan studi pendahuluan yang dilakukan di Puskesmas Jetis Kota Yogyakarta, dari tanggal 26 Oktober sampai 17 November 2014, diambil 10 sampel bayi. Setelah dilakukan penimbangan dan dilakukan pembandingan, diperoleh hasil sebagai berikut: empat bayi yang mendapat ASI eksklusif mengalami kenaikan berat badan antara 4.800-6.100 gram dan enam bayi yang mendapat ASI parsial mengalami kenaikan berat badan antara 3.350-5.250 gram. Tujuan penelitian untuk mengetahui perbedaan kenaikan berat badan pada bayi yang mendapat ASI eksklusif dan ASI parsial di Puskesmas Jetis Kota.

\section{BAHAN DAN METODE}

Jenis penelitian ini penelitian induktif dengan pendekatan cross-sectional. Pengambilan sampel dilakukan dengan teknik sampling jenuh. Populasi dalam penelitian ini adalah semua ibu yang mempunyai bayi berumur 8-10 bulan yang berkunjung dan berada di wilayah Puskesmas Jetis Kota Yogyakarta. Pengambilan sampel dilakukan dengan teknik sampling jenuh sejumlah 20 responden. Sampel dalam penelitian ini juga harus memenuhi kriteria inklusi: Ibu yang mempunyai bayi berumur 8-10 bulan dan memeriksakan diri ke Puskesmas Jetis Kota Yogyakarta, bayi dalam keadaan sehat, berat bayi lahir $\geq 2.500$ gram, bayi yang pernah mendapatkan ASI, memiliki buku KIA dan diisi dengan lengkap, ibu yang bersedia menjadi responden dengan cara menandatangi informed consent, dapat berkomunikasi dengan baik, dan kriteria eksklusi: Ibu yang tidak bersedia menjadi responden, ibu yang tidak bisa berkomunikasi dengan baik (tunarungu, tunawicara, tunanetra, dsb), bayi sedang sakit atau tidak sehat, bayi berusia $<8$ bulan atau $<10$ bulan, berat bayi lahir $<2.500$ gram, bayi belum pernah mendapatkan ASI, tidak memiliki buku KIA atau memiliki buku KIA namun tidak diisi dengan lengkap. Penelitian dilakukan di Puskesmas Jetis Kota Yogyakarta pada tanggal 23 Februari sampai 23 Maret 2015. Alat ukur yang digunakan adalah timbangan berat badan bayi dan buku KIA. Analisis data dalam penelitian ini menggunakan analisis " $t$ " test.

\section{HASIL DAN BAHASAN}

\section{Karakteristik Responden}

Karakteristik responden yang didapat yaitu bayi yang berumur 9 bulan yang mendapat ASI eksklusif atau yang mendapat ASI parsial pada penelitian ini dapat dilihat pada Tabel 1.

Tabel 1. Karakteristik Responden

\begin{tabular}{lccc}
\hline $\begin{array}{c}\text { Umur } \\
\text { (bulan) }\end{array}$ & ASI Eksklusif & ASI Parsial & Jumlah \\
\hline 8 & - & - & - \\
9 & 10 & 10 & 20 \\
10 & - & - & - \\
Jumlah & 10 & 10 & 20 \\
\hline
\end{tabular}

Sumber: Data Primer Tahun 2015

Berdasarkan Tabel 1 didapatkan responden sejumlah 20 bayi, masing-masing 10 bayi yang mendapat ASI eksklusif dan 10 bayi yang mendapat ASI parsial. ASI eksklusif merupakan pemberian ASI tanpa makanan lain, cairan, dan air, diberikan sedini mungkin setelah selesai proses persalinan dan diberikan tanpa jadwal sampai bayi berumur enam bulan(5), dengan pengecualian cairan yang mengandung suplementasi vitamin dan mineral serta obat(6).

ASI eksklusif adalah bayi hanya diberi ASI saja selama 6 bulan, tanpa tambahan cairan lain seperti susu formula, jeruk, madu, air teh, dan air putih, serta tanpa tambahan makanan padat seperti pisang, bubur susu, biskuit, bubur nasi, dan nasi tim. Setelah 6 bulan baru diberi makanan pendamping ASI (MPASI). ASI dapat diberikan sampai anak berusia 2 tahun atau lebih(7). ASI eksklusif adalah pemberian ASI saja pada bayi sampai usia 6 bulan tanpa tambahan cairan ataupun makanan lain(8).

ASI dapat diberikan sampai bayi berusia 2 tahun. Bayi usia 0-6 bulan yang tidak diberi ASI Eksklusif cenderung lebih banyak yang mengalami kelebihan berat badan dengan rata-rata pertambahan/kenaikan 1.240 gram/bulan pada usia 0-3 bulan(9). Hal ini dapat dinyatakan bahwa berat badan bayi yang 
mendapat ASI eksklusif lebih ringan dibanding bayi yang mendapat ASI non eksklusif/parsial sampai usia 6 bulan. Hal ini bukan berarti bahwa berat badan yang lebih besar pada bayi yang mendapat ASI non eksklusif/parsial lebih baik dibanding bayi yang mendapat ASI eksklusif.

Ketika bayi berusia 6-12 bulan, ASI bertindak sebagai makanan utama bayi karena mengandung lebih dari $60 \%$ kebutuhan bayi. Guna memenuhi semua kebutuhan bayi, maka ASI perlu ditambah dengan makanan pendamping ASI (MP-ASI). Jika seorang bayi tidak diberi ASI dan diganti dengan susu formula, maka bayi tidak akan mendapat kekebalan, serta akan kekurangan gizi, dengan tidak adanya zat antibodi, maka bayi akan mudah terkena berbagai penyakit sehingga meningkatkan angka kematian bayi(10).

ASI parsial (partial breastfeeding) adalah memberikan makanan pada bayi dengan cara sebagian menyusui sebagian lagi susu buatan, sereal, atau makanan lain(11). Sedangkan WHO mendefinisikan menyusui parsial adalah menyusui bayi serta diberikan makanan buatan selain ASI, baik susu formula, bubur atau makanan lainnya sebelum bayi berumur 6 bulan baik diberikan secara kontinyu, maupun diberikan sebagai makanan prelaktal.

\section{Berat Badan Lahir Bayi}

Data berat badan lahir bayi di Puskesmas Jetis dibagi atas tiga kelompok, yaitu: berat bayi antara 2.500-3.000 gram, 3.100-3.500 gram, dan 3.6004.000 gram.

Tabel 2. Hasil Pengolahan Data Sekunder Berat Badan Lahir Bayi

\begin{tabular}{ccc}
\hline Berat Badan (gram) & $\mathbf{f}$ & $\%$ \\
\hline $2.500-3.000$ & 9 & 45 \\
$3.100-3.500$ & 10 & 50 \\
$3.600-4.000$ & 1 & 5 \\
\hline
\end{tabular}

Sumber: Data Sekunder Tahun 2015

Berdasarkan Tabel 2 yang merupakan hasil pengolahan data sekunder dari buku KIA yang diperoleh berdasarkan penimbangan berat badan bayi ketika lahir. Berat badan lahir bayi terbanyak berkisar antara $3.100-3.500$ gram, yaitu $50 \%$, berat badan lahir bayi antara 2.500-3.000 gram adalah sebanyak $45 \%$. Sedangkan berat badan lahir bayi antara 3.600-4.000 gram hanya sebanyak $5 \%$.

Berat badan lahir normal bayi sekitar 2.5003.500 gram, apabila kurang dari 2.500 gram dikatakan bayi memiliki berat badan lahir rendah (BBLR), sedangkan bila lebih dari 3.500 gram dikatakan makrosomia.
Pengukuran berat badan digunakan untuk menilai hasil peningkatan atau penurunan semua jaringan yang ada pada tubuh, misalnya tulang, otot, lemak, organ tubuh, dan cairan tubuh sehingga dapat diketahui status keadaan gizi atau tumbuh kembang anak. Selain itu, berat badan juga dapat digunakan sebagai dasar perhitungan dosis dan makanan yang diperlukan dalam tindakan pengobatan. Faktor yang mempengaruhi berat badan bayi meliputi nutrisi pada bayi, status sosial ekonomi, dan status kesehatan bayi(12).

\section{Hasil Berat Badan Bayi Umur 9 Bulan}

Hasil pengolahan data primer berdasarkan penimbangan bayi pada umur 9 bulan yang mendapat ASI Eksklusif dan Parsial dapat dilihat pada Tabel 3.

Tabel 3. Hasil Pengolahan Data Primer Berat Badan Bayi Setelah Memperoleh ASI

\begin{tabular}{lccc}
\hline \multicolumn{1}{c}{ Jenis ASI } & $\begin{array}{c}\text { Kenaikan Berat } \\
\text { Badan Bayi (gram) }\end{array}$ & $\mathbf{f}$ & $\%$ \\
\hline Eksklusif & $3.000-4.000$ & - & \\
& $4.100-5.000$ & 6 & 60 \\
& $5.100-6.000$ & 3 & 30 \\
& $6.100-7.000$ & 1 & 10 \\
Parsial & $3.000-4.000$ & 2 & 20 \\
& $4.100-5.000$ & 2 & 20 \\
& $5.100-6.000$ & 6 & 60 \\
Jumlah & $6.100-7.000$ & - & \\
\hline
\end{tabular}

Sumber: Data Primer Tahun 2015

Berdasarkan Tabel 3 yang merupakan hasil pengolahan data primer berdasarkan penimbangan bayi pada umur 9 bulan, dikarenakan pada saat penelitian hanya didapatkan sampel penelitian bayi yang berumur 9 bulan saja, dan bayi telah memperoleh ASI, baik ASI eksklusif maupun ASI parsial.

Kenaikan berat badan pada bayi yang mendapat ASI eksklusif terbanyak adalah berkisar antara 4.100-5.000 gram yaitu sebanyak $60 \%$. Sedangkan kenaikan berat badan pada bayi yang mendapat ASI parsial terbanyak adalah berkisar antara 5.100-6.000 gram yaitu $60 \%$. Pertumbuhan berat badan bayi usia 0-6 bulan mengalami penambahan $150-210 \mathrm{gram} /$ minggu dan berdasarkan kurva pertumbuhan yang diterbitkan oleh National Center for Health Statistics (NCHS), berat badan bayi akan meningkat dua kali lipat dari berat lahir pada akhir usia 4-7 bulan(13).

Pengolahan data hasil perbandingan berat badan lahir bayi dengan berat badan bayi setelah mendapat ASI dan pengujian hipotesis komparatif dua sampel berpasangan pengolahan data sampel menggunakan t-test (uji t untuk dua sampel yang 
berpasangan). Rata-rata (mean) berat badan lahir bayi dan berat badan bayi setelah penelitian dapat dilihat pada Tabel 4.

Tabel 4. Rata-Rata Dua Sampel Berpasangan dari Berat Badan Bayi

\begin{tabular}{lccc}
\hline \multicolumn{1}{c}{ Jenis ASI } & Jumlah & Mean & n \\
\hline Eksklusif & 82 & 8,2 & 10 \\
Parsial & 79 & 7,99 & 10 \\
\hline
\end{tabular}

Sumber: Data Primer Tahun 2015

Berdasarkan Tabel 4 terlihat ringkasan statistik dari rata-rata sampel $X_{1}$ (Berat badan bayi yang mendapat ASI eksklusif) dan $X_{2}$ (berat badan bayi yang mendapat ASI parsial) menunjukkan sampel 8.200 gram dan 7.900 gram.

Jumlah s (SD sampel) berat badan bayi yang mendapat ASI eksklusif dan berat badan bayi yang mendapat ASI parsial dapat dilihat pada Tabel 5. Dari jumlah s (SD sampel tiap-tiap sampel berat badan bayi dengan $\mathrm{X}_{1}$ (Berat badan bayi yang mendapat $\mathrm{ASI}$ eksklusif) dan $\mathrm{X}_{2}$ (berat badan bayi yang mendapat ASI parsial) menunjukkan sampel 2.480 .000 dan 78.579.900.

Setelah dilakukan pengolahan data didapatkan pada Tabel 5 terlihat rata-rata berat badan bayi dengan perbandingan 76.099 .000 sehingga nilai antara $\mathrm{X}_{1}$ dan $\mathrm{X}_{2}$ tidak signifikan.

Tabel 5. Jumlah "s" (SD sampel) dari Dua Sampel Berpasangan

\begin{tabular}{lcc}
\hline \multicolumn{1}{c}{ Jenis ASI } & $(\mathbf{X}-\overline{\mathbf{x}})^{2}$ & $\mathbf{n}$ \\
\hline Eksklusif & 2.480 .000 & 10 \\
Parsial & 78.579 .900 & 10 \\
\hline
\end{tabular}

Sumber: Data Primer Tahun 2015

Berdasarkan perhitungan rumus, didapatkan t-hitung adalah: 0,260 dan t-tabel adalah: 2,101 (t-hitung lebih kecil dari t-tabel), maka Ho diterima dan Ha ditolak, yang artinya tidak terdapat perbedaan berat badan yang signifikan antara bayi yang mendapat ASI eksklusif dengan bayi yang mendapat ASI parsial.

Didapatkan hasil bahwa kenaikan rata-rata berat badan bayi yang mendapat ASI eksklusif adalah 8.200 gram dan kenaikan rata-rata berat badan bayi yang mendapat ASI parsial 7.990 gram, terdapat kenaikan berat badan 210 gram lebih tinggi pada bayi yang mendapat ASI eksklusif. Hal ini tidak sesuai dengan data pada lampiran yaitu nilai t-hitung tenyata lebih kecil dari t-tabel $(0,260<2,101)$, yang berarti tidak terdapat perbedaan kenaikan berat badan antara bayi yang mendapat ASI eksklusif dengan bayi yang mendapat ASI parsial. Pada penelitian ini, jumlah responden yang sedikit mempengaruhi hasil penelitian, dapat dimungkinkan apabila jumlah bayi yang diteliti lebih dari 30 responden, akan didapatkan penelitian dengan hasil yang berbeda. Berdasarkan teori, pada distribusi "t", setiap harga "n" yang berbeda akan mempunyai distribusi " $t$ " yang berbeda. Distribusi " $\mathrm{t}$ " adalah distribusi teoritis dengan variabel random kontinyu yang menyerupai distribusi normal.

Selain jumlah responden, faktor-faktor yang mempengaruhi berat badan bayi juga dapat memungkinkan perolehan hasil yang berbeda dalam penelitian ini. Faktor-faktor yang mempengaruhi pertumbuhan bayi dipengaruhi oleh dua faktor utama yaitu faktor internal seperti biologis, termasuk genetik, dan faktor eksternal seperti status gizi(14). Penelitian ini hanya terbatas pada berat badan bayi ketika lahir dan kemudian dibandingkan dengan berat badan saat penelitian tanpa mempertimbangkan faktor internal dan eksternal tersebut. Sebagai contoh, status gizi bayi ataupun riwayat penyakit yang pernah diderita bayi memungkinkan dapat memberi pengaruh terhadap kenaikan berat badan bayi, sehingga saat dilakukan penelitian, berat badan bayi yang memiliki status gizi baik akan berbeda dengan bayi yang memiliki status gizi kurang baik.

\section{SIMPULAN DAN SARAN}

Berdasarkan paparan hasil analisis penelitian dan pembahasan yang telah dilakukan dapat disimpulkan bahwa Tidak terdapat perbedaan kenaikan berat badan pada bayi yang mendapat ASI eksklusif dan bayi yang mendapat ASI parsial.

Saran bagi ibu menyusui hendaknya lebih memahami betapa pentingnya memberikan ASI eksklusif pada bayi agar tidak terjadi komplikasi yang dapat timbul akibat tidak mendapat ASI eksklusif.

\section{RUJUKAN}

1. Dewi VNL, Tri S. Asuhan Kebidanan pada Ibu Nifas. Jakarta: Salemba Medika; 2013.

2. Kementerian Kesehatan RI. Info Datin Situasi dan Analisis ASI. Jakarta: Kementrian Kesehatan $\mathrm{RI} ; 2014$.

3. Departemen Kesehatan Bantul. Profil Departemen Kesehatan Kabupaten Bantul Tahun 2011. Bantul: Departemen Kesehatan Bantul; 2011.

4. Dinas Kesehatan Sleman. Profil Kesehatan Kabupaten Sleman Tahun 2013. Yogyakarta: Dinas Kesehatan; 2013.

5. Liu JZ. The Association between Cesarean Delivery on Maternal Request and Method of Newborn Feeding in China. PloS One. 2012;7:36-7. 
6. Tamiru TB. Sub-optimal Breastfeeding of Infants During the First Six Months and Associated Factors in Rural Communities of Jimma Arjo Woreda, Southwest Ethiopia. BMC Public Health. 2012;12:363-77.

7. Kristiyansari W. ASI, Menyusui dan SADARI. Yogyakarta: Nuha Medika; 2009.

8. World Health Organization (WHO). Global Strategy for Infant and Young Child Feeding: The Optimal Duration of Exlusive Breastfeedig. Ganeva: WHO; 2005:7-8.

9. Sugiarsi S. Studi Case Control Kenaikan Berat Badan pada Kelompok Bayi Usia 0-6 bulan yang Diberi ASI Eksklusif dan Non ASI Eksklusif di Kecamatan Sukoharjo. Maternal. 2010 Apr;2:133.

10. Astutik RY. Payudara dan Laktasi. Jakarta: Salemba Medika; 2014.
11. Sofyana H. Perbedaan Dampak Pemberian ASI Eksklusif dan Non Eksklusif Terhadap Perubahan dan Ukuran Antropometri dan Status Imunitas pada Neonatus di Rumah Sakit Umum Daerah (RSUD) Al Ihsan Provinsi Jawa Barat. Depok: Fakultas IImu Keperawatan Universitas Indonesia; 2011.

12. Hidayat AA. Pengantar IImu Kesehatan Anak untuk Pendidikan Kebidanan. Jakarta: Salemba Medika; 2008.

13. Wong D. Buku Ajar Keperawatan Pediatrik. 6th ed. 1st vol. Jakarta: EGC; 2008.

14. Kurniatika R. Peningkatan Berat Badan Bayi Baru Lahir yang Mendapatkan ASI Eksklusif Setelah 1 Bulan di Klinik Bersalin Lolly Medan. Progam D-IV Bidan Pendidik Fakultas Keperawatan Universitas Sumatera Utara; 2012. 